\title{
A retrospective study (2015-2019) of avian salmonellosis diagnosed at the Central Diagnostic Laboratory of the National Veterinary Institute, Vom, Plateau State, Nigeria
}

\author{
Barde Israel Joshua ${ }^{1 \star}$, Ndam Daushe Nangor², Oladele Blessing Sunday ${ }^{3}$, Fatihu Mohammed \\ Yakasai3 and Abdu Paul Ayuba ${ }^{3}$
}

${ }^{1}$ Veterinary Pathology Division, National Veterinary Research Institute, Vom, Plateau State, Nigeria. ${ }^{2}$ Federal College of Animal Health and Production Technology, Vom, Plateau State, Nigeria. ${ }^{3}$ Faculty of Veterinary Medicine, Ahmadu Bello University, Zaria, Kaduna State, Nigeria.

*Corresponding author. Email: israelbarde@yahoo.com; Tel: +2348066655055.

Copyright (@) 2021 Joshua et al. This article remains permanently open access under the terms of the Creative Commons Attribution License 4.0, which permits unrestricted use, distribution, and reproduction in any medium, provided the original work is properly cited.

Received 30th April, 2021; Accepted 14th June, 2021

\begin{abstract}
Salmonella organisms are widely distributed in nature and survive well in a variety of food and contamination and can occur at multiple steps along the food chain. The study was conducted at the Central Diagnostic Laboratory of the National Veterinary Research Institute (N.V.R.I) located in Vom Jos South Local Government Area of Plateau State Nigeria. Information was obtained via postmortem records and laboratory results that isolated Salmonella species were retrieved and analyzed retrospectively in the study area for five years. Descriptive statistics were used to analyze data while tables were used for result proportions presented in percentages. A total of 2512 cases of poultry diseases were documented for a period of five years from 2015 to 2019 with an average of 502.4 cases annually. A total of 436 of salmonellosis was documented during the period under review and an average of 87.2 cases annually. $24.4 \%$ prevalence was recorded in 2018 and $12.4 \%$ in 2015. 2019 had the highest prevalence of 28.4 with an average avian salmonellosis prevalence of $19 \% .24 .6 \%$ avian salmonellosis was recorded in the age bracket of 5 to 8 weeks, $29.5 \%$ was documented in the age bracket of 9 to 12 weeks which was the second highest and $33.3 \%$ in the age bracket of 0 to 4 which was the highest. Avian salmonellosis affects all types of birds. Out of 436 positive avian salmonellosis cases recorded in the period under review, 251 were layers while 156 were broilers with 29 being local birds and cockerels. This study does explicitly indicate that avian salmonellosis is highly prevalence in the study area and this could play a great role in lowering poultry productivity in the study area, thereby highlighting the need for effective health programs like good biosecurity practices and vaccination in order to boost poultry production.
\end{abstract}

Keywords: Avian salmonellosis, diagnosis, Nigeria, Vom.

\section{INTRODUCTION}

The Food and Agricultural Organization (FAO) estimated the population of poultry in Nigeria to be 150 million which is three times the population of all domestic animals combined (FAO, 2015). In spite of this large population of domestic animals and poultry, the animal protein requirement for the country is still very low and inadequate. Therefore, there is need for great increase in livestock and poultry production. The poultry industry in Nigeria cannot thrive well due to some problems such as disease and poor quality feed which affect the cost of production. The major problem is disease which accounts for great losses in poultry production (Emenna et al., 2019).

Though in Nigeria, there is slight increase in hen egg production as in 2011 which was total at 636,000 metric tons (MT) and valued at N8527.49 million ranking 19th in the world and first in Africa (FAO 2015). Despite the rise in egg production, avian Salmonellosis remains a major constraint to poultry production in all parts of Nigeria 
(Mbuko et al., 2009).

Salmonella was first isolated and described by Daniel $\mathrm{E}$ Salmon and can be described as a rod shape gram negative facultative non spore forming bacilli which belongs to the family Enterobacteriaceace (Popoff et al., 2003). The genus salmonella is divided into two species Salmonella enterica and $S$. bongori. Salmonella enterica itself consists of six sub species which are S. enterica sub specie enterica, sub specie arizona's, sub specie diarizone, sub specie indica and sub specie houtane or i, ii, iiia, iiib, iv and vi respectively (Barde et al., 2015). All salmonella are actively motile (Cheesbrough et al., 2000).

Salmonellosis is one of the most common infectious diseases in the world in human and animals and also the most frequently isolated food borne pathogen and causes a wide range of disease such as enteric fever, gastroenteritis and bacteremia (FAO, 2015; Shivaprasad, 2000). Salmonella organisms are widely distributed in nature and survive well in a variety of food and contamination can occur at multiple steps along the food chain (Shivaprasad, 2000).

Infection with salmonella can occur through inadequate cleaning and disinfection of poultry houses, presence of carrier rodents and insects, litters, water, dust, equipment and feed (Shivaprasad 1997; Shivaprasad, 2000). Infection in day old chicks could be vertical from infected breeder flocks or horizontally transmitted during hatching, loading and transporting to the farm. Salmonella can be found in poultry egg and dairy product (Silva et al., 2015). Outbreaks of salmonellosis has also been linked to wide varieties of fresh fruit and vegetables such as apple, cantaloupe, alfalfa, sprout, mangos, cilantro, unpasteurized orange juice, tomato, melon, celery and parsley (FAO, 2015).

Post mortem lesions in birds include unabsorbed yolk sac, congested lung, dark and swollen hemorrhagic liver, inflamed ceca and chicks may die after one or two days of age. In hens, there is irregular ovary, cystic, deformed and pendeculated with prominent thickened stalks. Sometimes, the ovary is inactive with small pale and underdeveloped ova (Barde et al., 2015).

Each year, an estimated 1.3 billion Salmonellosis cases resulting in about 3 million deaths worldwide has been reported. In spite of the importance of poultry as the major element of protein in the human, food borne outbreaks of salmomella organisms occur worldwide with associated anti-microbial susceptibility problems (Yhiler and Bassey, 2015). Non typhoidal salmonella (NTS) are zoonotic agents and a wide variety of animals have been identified as reservoirs. Poultry are considered as one of the most common vehicles of human salmonellosis (Fashae et al., 2010). Over the years, attempts in controlling salmonellosis has not been very successful because it is widely distributed in nature and can survive in varieties of food (Silva et al., 2015). Poultry farmers still experience great losses by way of mortality, morbidity and drops in egg production due to Salmonella infection despite huge amounts spent on vaccination and medication. Salmonellosis in poultry causes heavy economic loss due to mortality and reduced production (Khan et al., 1998; Khan et al., 2014; Tadele et al., 2014; Barde et al., 2017). There is paucity of data regarding the occurrence of salmonella in the study area, thus, knowing the frequency and rate of occurrence is the reason for embarking on this study. Therefore, the aim of this study is to evaluate a five year retrospective study (2015-2019) of avian salmonellosis diagnosed at the Central Diagnostic Laboratory (CDL) of the National Veterinary Research Institute, (NVRI) Vom, Plateau State.

\section{METHODOLOGY}

\section{Study location}

The study was conducted at the CDL of the NVRI which is located in Vom, Jos South Local Government Area of Plateau State Nigeria.

\section{Type of sample}

Information was obtained via postmortem records findings in the CDL of the NVRI Vom.

\section{Size of sample}

Post mortem record findings and laboratory results positive for Salmonella species ranging from 2015 to 2019 were used. The records of diseases as presented and diagnosed at the CDL during the five years (2015-2019) period was retrieved and analyzed retrospectively. Descriptive statistics was used to analyze data while tables were used for result proportion presented in percentages.

\section{Data analysis}

Association between infection and other factors such as type of bird and age were accessed using Chi-square. Results are presented in tables.

\section{RESULTS AND DISCUSSION}

The total of 2512 cases of poultry diseases were documented for a period of five years from 2015 to 2019 with an average of 502.4 cases annually. A total of 436 of salmonellosis was documented during the period under review following laboratory bacteriological isolation of Salmonella species, and an average of 87.2 cases annually was recorded (Table 1). In Table 1, 24.4\% prevalence was recorded in 2018 and 12.4\% in 2015. 2019 
Table 1. Association between avian Salmonellosis and year.

\begin{tabular}{lcccc}
\hline Variable year & No examined & No. positive & Percentage (\%) prevalence & p-value \\
\hline 2015 & 797 & 99 & 12.4 & \\
2016 & 537 & 88 & 15.4 & \\
2017 & 499 & 78 & 15.6 & p $<0.001$ \\
2018 & 294 & 72 & 24.5 & \\
2019 & 349 & 99 & 28.4 & \\
Grand total & 2512 & 436 & 96.3 & \\
\hline
\end{tabular}

Table 2. Association between avian Salmonellosis and age of bird.

\begin{tabular}{lcccc}
\hline Age & No. examined & No. positive & Percentage (\%) prevalence & p-value \\
\hline $0-4$ & 315 & 105 & 33.3 & \\
$5-8$ & 435 & 107 & 24.6 & $\mathrm{p}<0.001$ \\
$9-12$ & 353 & 104 & 29.5 & \\
13 above & 1409 & 120 & 7.4 & \\
Grand total & 2512 & 436 & 96.3 & \\
\hline
\end{tabular}

Table 3. Association between avian Salmonellosis and type of bird.

\begin{tabular}{lcccc}
\hline Type of bird & No. examined & No. positive & Percentage (\%) prevalence & p-value \\
\hline Layers & 1934 & 251 & 13.0 & \\
Broilers & 535 & 156 & 29.2 & $\mathrm{p}<0.001$ \\
Others & 43 & 29 & 67.5 & \\
Grand total & 2512 & 436 & 96.3 & \\
\hline
\end{tabular}

has the highest prevalence of 28.4 with an average avian Salmonellosis prevalence of $19 \%$ which agrees with the report of Okwori et al. (2007) who recorded similar prevalence.

In Table 2, 24.6\% avian salmonellosis was recorded in the age bracket of 5 to 8 weeks, $29.5 \%$ was documented in the age bracket of 9 to 12 weeks which is the second highest and $33.3 \%$ in the age bracket of 0 to 4 weeks which is the highest. This could be as a result of low or weak or underdeveloped immune system in the young birds. This agrees with the report of Shivaprasad (1997) and Shivaprasad (2000) who started that young birds whose immune system is underdeveloped could be highly susceptible to Salmonella infection.

Table 3 shows that avian salmonellosis affects all types of birds. Out of 436 positive avian Salmonellosis cases recorded in the period under review, 251 were layers while 156 were broilers with 29 being others (local birds and cockerels). This is so because mostly layers (1935), broilers (535) and others (43) were examined respectively.

\section{Conclusion and Recommendations}

This study does explicitly indicate the significance that avian Salmonellosis is highly prevalence in the study area and this could play a great role in lowering poultry productivity in the study area, thereby highlighting the need for effective health programs like good biosecurity practices and vaccination in other to boost poultry production. Depopulation of infected flocks have enormously reduced the prevalence of the disease in other countries though it is hardly practiced in Nigeria because of the cost implication on government but it is worth trying, to reduce avian Salmonellosis in the country.

Poultry famers are advised to vaccinate their birds at appropriate time. Farmers should institute and intensify good biosecurity measures in their farms to minimize horizontal transmission. Commercial poultry farmers are also advised to site their farms away from residential areas to reduce chances of diseases in their farms.

\section{CONFLICT OF INTERESTS}

The authors declare that they have not conflict of interest.

\section{REFERENCES}

Barde, I. J., Bale, J. O. O., Fatihu, M. Y., Dashe, Y. G., Oluwadare, M. L., Ugbe, D. A., Oladele, B. S., \& Okewole, P. A. (2017). Clinical signs associated with experimental infection 
of Salmonella enterica serovar Gallinarum in Japanese quail (Coturnix coturnix japonica). Vom Journal of Veterinary Science, 12, 49-56.

Barde, I. J., Bale, J. O. O., Oladele, S. B., Fatihu, M. Y., Kumbish, P. R., Chukwu, D. I., Rimfa, A. G., Akanbi, B. O., Moses, G. D., Ahmed, J. S., Okewole, P. A. (2015). Gross and histopathological changes in Japanese quail (Coturnix coturnix Japonica) experimentally infected with Salmonella enterica serovar Gallinarum. Animal and Veterinary Sciences, 3(3), 8488.

Cheesbrough, M. (2000). Microbiological test: District laboratory practice in tropical countries. In: Cremer, A., \& Evan, G. (eds). Cambridge University Press, UK, Pp. 1-226.

Emenna, P. E., Eze, D. C., Chah, F. K., Okoye, J. O. A., Ihejioha, J. I., Sati, M. N., Onyema, I., Okorie-Kanu, C., DzikwiEmennaa, A. A., Chidiebere, U., \& Barde, I. J. (2019). Haematological and Serum Biochemistry Profile of Cockerels Experimentally Infected with Salmonella enterica Serovar Zega. Open Journal of Veterinary Medicine, 9(12), 171-184.

Fashae, K. J. (2010). Antimicrobial susceptibility and serovars of salmonella in chicken and humans in Ibadan, Nigeria. Journal of Infected Developed Countries, 34(8), 484-494.

Food and Agricultural Organization (FAO) (2015). Risk assessment of Salmonella in eggs and broilers chickens. (Microbiology assessment series 2). United Nation World Health Organization, 2, 302.

Khan, A., Bari, A. S. M., Islam, M. R., Das, P. M., \& Ali, M. Y. (1998). Pullorum disease in semi mature chickens and its experimental pathology. Bangladesh Veterinary Journal, 32, 124-128.

Khan, A., Mahmoud, M. S., Hussain, I., Saddique, F., Rafique, A., Iqbal, A., \& Abbas, R. Z. (2014). Bacteriological and Epidemiological investigation of pullorum disease in selected poultry farms of Faisalabad Pakistan. Global Veterinarian, 12(4),455-460.

Mbuko. I. J., Raji, M. A., Ameh, J., Saudi, L., Musa, W. I., \& Abdu, P. A. (2009). Prevalence and seasonality of fowl typhoid disease in zaria-kaduna state. Nigeria Journal of Bacteriology Research, 1(1), 004-005.
Okwori, A. E., Hasimil G. A., Adetunji J. A., Akaka I. O., \& Junards S. A (2007). Serological survey of Salmonella gallinarum antibodies in chicken around Jos, Plateau State. Nigerian online Journal health Allied Sciences. 6(2), 1-6.

Popoff, M. Y., Bockemuhl. J., and Gheesging. L. L., (2003). Antigenic for molars of salmonella serovars, $8^{\text {th }}$ revision. WHO collaborating centre for reference and research on Salmonella. Supplement 2001 (no. 45) to the Kauffmann-White scheme. Research in Microbiology, 154(3),173-174.

Salvaraj, R. K., Shanmugasundram, R., Klasing, K. C. (2010). Effects of dietary litein and pufa on PPRA and RXR isomer expression in chickens during an inflammatory response. Comparative Biochemistry and Physiology Part A: Molecular \& Integrative Physiology, 157(3), 198-203.

Shivaprasad, H. L. (2000). Fowl typhoid and Pullorum disease. Revue Scientifique et Technique (International Office of Epizootics), 19(2), 405-424.

Shivaprasad, L. H., (1997). Pullorum disease and fowl typhoid. In: Calnex, B. W., Barnes, H. J., Beard C. W., McDogald, L. R., \& Siaf, Y. M. (eds). Disease of poultry (10th edition). Lower State University Press, America, Lowa. Pp. 83-121.

Silva, N. F., Magalhães, J. M., Oliva-Teles, M. T., \& DelerueMatos, C. (2015). A potentiometric magnetic immunoassay for rapid detection of Salmonella typhimurium. Analytical Methods, 7(9), 4008-4011.

Tadele, G., Asrade, B., Bayleyegn G., \& Ali, M. S (2014). Seroprevelance of fowl typhoid and Pullorum disease from apparently healthy chickens in eastern Ethiopia. Journal of veterinary science and Technology, 3,156.

Yhiler, N. Y., \& Bassey, B. E. (2015). Antimicrobial susceptibility patterns of Salmonella species from sources in poultry production settings in Calabar, Cross River state. Nigeria American Journal of Health Research, 3(2), 76-81. 